\title{
Specially Structured Flow Shop Scheduling in Two Stage with Concept of Job Block and Transportation Time to Optimize Total Waiting Time of Jobs
}

\author{
Deepak Gupta $^{\# 1}$, Bharat Goyal ${ }^{* 2}$ \\ "Department of Mathematics, Maharishi Markandeshwar (Deemed to be University) \\ Mullana (Ambala), Haryana, India \\ ${ }^{1}$ guptadeepak20003@gmail.com \\ *Department of Mathematics, G.S.S.D.G.S. Khalsa College, Patiala, Punjab, India \\ 2bhartu89@gmail.com
}

\begin{abstract}
Flow shop scheduling, where the machines are prearranged in order that the flow of each and every of the products that are processed in them is unidirectional. In the present paper Flow shop scheduling models in two stage are well thought of. The problem is specially structured with the idea that maximum of equivalent processing time on first machine remains always less than the minimum of equivalent processing time on second machine. The intention of the study is to find the schedule which lessens the total of the waiting time of all the jobs. The time to transport jobs from first machine to second machine is considered separately and two jobs considered as a group job. An Algorithm to optimize the desired function and the program in $\mathrm{C}++$ language is proposed. Numerical example by applying the algorithm proposed is solved.
\end{abstract}

Key words - Flow shop scheduling, Job block, Processing time, Transportation time, Waiting time of jobs.

\section{INTRODUCTION}

The problem of deciding when to perform given jobs with the purpose of optimizing a function while taking attention of chronological constraints and be located in the limitation of resources is known as scheduling. The procedure of sharing the same pre described order of all the machines by the jobs is known as Flow Shop Scheduling. In the present paper we talk about the $\mathrm{n} \times 2$ specially structured Flow shop scheduling in which it is assumed that minimum of the equivalent processing time on second fictitious machine can never be less than to the maximum of equivalent processing time on first fictitious machine. The intention of study is minimization of the total of the waiting time of jobs. When the jobs come for the processing, the waiting time for their turn on the first machine is considered to be zero. But in order to process a job on second machine they may have to wait for their turn for many reasons such as the previous job can take some time for the operation on second machine, machine can take time to set up, break down in the machine etc. This time which is devoted in waiting for the processing of job on the second machine is known as the waiting time of the job. And the sum of all the waiting time of jobs is known as the total of the waiting time of all the jobs.

\section{LITERATURE SURVEY}

The Johnson's algorithm [1] for Flow Shop Scheduling problem for n-job, 2-machine and 3-machine to lessen the total elapsed time is popular among the analytical approaches that are used for solving n-job, 2 and 3machine scheduling problem. The n-job, m-machine problem has been studied very wisely by many researchers. Ignall E. and et.al. [2] applied branch and bound technique for the permutation flow shop scheduling with the intention of minimization of makespan. Maggu P.L. and et. al. [4] made an effort to widen the study by initiating the notion of equivalent job for job block. Bhatnagar V.and et. al.[5] investigate the n-job ,2 machine flow shop scheduling models with the intention to optimize the total of the waiting times of all the jobs. Further to optimize the total elapsed time studies are developed by Singh T. P. and et. al.[6], [9] by taking into account the diverse parameters such as time to transport jobs, time of breakdown machines, group job restrictions and job block etc. Narain L. and et. al. [11] considers the optimality as to optimize the cost of the machines that are hired on rent by making a group job of two jobs. Further Gupta D. and et.al. [15] widened the study by considering specially structured Flow shop scheduling models in two stage to minimize the cost which is consumed on rent of machines. Gupta D. and et. al.[16] while studying the specially structured two stage flow shop scheduling models has also considered the transportation time separated from the processing time with the intention to achieve the schedule which lessens the rental cost of the machines. Gupta D. and et.al. [14],[17],[18] studied Flow Shop Scheduling models in two stage with the idea to optimize the total of the waiting time of all the jobs where the parameters like job block concept, time to transport jobs from first machine to second machine are well thought of. 
This paper is an addition in the study made by Gupta D. and et.al. [18] in the sense that we have taken into consideration the concept of making a job block for two jobs.

\section{PRACTICAL SITUATION}

Industrialized units play an imperative role in the monetary growth of a country. Flow shop scheduling happens in banks, airports, service stations etc. Regular working in industries and factories has diverse jobs which are to be practiced on various machines. The idea of lessening the total of the waiting time for all the jobs may be a reasonable aspect from managers of Factory /Industry perspective when he has contract to made the work with less waiting with a viable party to finish the work.

\section{NOTATIONS}

$S_{j}:$ Schedule of the jobs.

$m_{1 j}$ : Time taken by first machine to process $\mathrm{j}^{\text {th }}$ job.

$m_{2 j}$ : Time taken by second machine to process $\mathrm{j}^{\text {th }}$ job.

$X_{j}^{\prime}$ : Equivalent processing time taken by machine $\mathrm{X}$ to process $\mathrm{j}^{\text {th }}$ job.

$Y^{\prime}{ }_{j}$ : Equivalent Processing time taken by machine $Y$ to process $\mathrm{j}^{\text {th }}$ job.

$t_{1 \rightarrow 2, j}$ : Time taken to transport $\mathrm{j}^{\text {th }}$ job from first machine to second machine.

$T_{a Y}$ : The time of the completion of job ' $a$ ' on machine $Y$.

$W_{\mu}$ : Waiting time of job $\mu$.

$W$ : Total of the waiting time of all the jobs.

\section{PROBLEM FORMULATION}

The machines $\mathrm{M}_{1}$ and $\mathrm{M}_{2}$ are dealing out $\mathrm{n}$ jobs in the sort $\mathrm{M}_{1} \mathrm{M}_{2}, m_{1 j}$ and $m_{2 j}$ are the relevant processing times of the $\mathrm{j}^{\text {th }}$ job and $t_{1 \rightarrow 2, j}$ is the time consumed in transporting $\mathrm{j}^{\text {th }}$ job from machine $\mathrm{M}_{1}$ to machine $\mathrm{M}_{2}$. The problem formulation in matrix form as defined in [6], [16] can be seen in TABLE I. Our goal is to come across a best possible sequence $S_{j}$ of jobs by considering two jobs $(1, \mathrm{~m})$ as a job block with the intention to optimize the total of the waiting time of all the jobs. The equivalent processing times $X_{{ }_{j}}$ and $Y^{\prime}{ }_{j}$ of $j^{\text {th }}$ job on Fictitious machines $X$ and $Y$ as defined by Singh T.P. [6], Gupta D. and et.al. [16], [18] are given by

$X^{\prime}{ }_{j}=m_{1 j}+t_{1 \rightarrow 2, j}$

$Y^{\prime}{ }_{j}=m_{2 j}+t_{1 \rightarrow 2, j}$

satisfying processing times structural relationship $\operatorname{Max}_{X}{ }_{j} \leq \operatorname{Min}_{Y^{\prime}}{ }_{j}$

\section{A. Assumptions}

In the given flow shop scheduling the following assumptions are made:

1) Machines $M_{1}$ and $M_{2}$ are processing $n$ jobs, firstly on machine $M_{1}$ then on machine $M_{2}$ and no passing is permissible.

2) At the same time no job will be processed by both of the machines.

3) The course of action of the machines can't be interrupted until a job which is in execution can't be completed.

4) Set-up time of machines, Break down interval of machines is negligible.

5) It is given two jobs $1, \mathrm{~m}$ as a block with priority of processing job $\mathrm{l}$ over job $\mathrm{m}$ in the block $(\mathrm{l}, \mathrm{m})$.

TABLE I. Problem Formulation in Matrix Form

\begin{tabular}{|c|c|c|c|}
\hline Job & Machine $\mathbf{M}_{\mathbf{1}}$ & Transportation time & Machine $\mathbf{M}_{\mathbf{2}}$ \\
\hline $\mathrm{j}$. & $\mathrm{m}_{1 \mathrm{j}}$ & $\mathrm{t}_{1 \rightarrow 2, \mathrm{j}}$ & $\mathrm{m}_{2 \mathrm{j}}$ \\
\hline 1. & $\mathrm{~m}_{11}$ & $\mathrm{t}_{1 \rightarrow 2,1}$ & $\mathrm{~m}_{21}$ \\
\hline 2. & $\mathrm{~m}_{12}$ & $\mathrm{t}_{1 \rightarrow 2,2}$ & $\mathrm{~m}_{22}$ \\
\hline 3. & $\mathrm{~m}_{13}$ & $\mathrm{t}_{1 \rightarrow 2,3}$ & $\mathrm{~m}_{23}$ \\
\hline$\ldots$. & $\ldots$. & $\ldots \ldots$ & $\ldots$. \\
\hline $\mathrm{n}$. & $\mathrm{m}_{1 \mathrm{n}}$ & $\mathrm{t}_{1 \rightarrow 2, \mathrm{n}}$ & $\mathrm{m}_{2 \mathrm{n}}$ \\
\hline
\end{tabular}




\section{B. Lemma}

Two machines $\mathrm{X}, \mathrm{Y}$ are handing out $\mathrm{n}$ jobs in sort $\mathrm{X} \mathrm{Y}$ among no passing is permissible. $\left\{X^{\prime}{ }_{j}\right\}_{j=1}^{n}$ and $\left\{Y^{\prime}{ }_{j}\right\}_{j=1}^{n}$ are the processing times of $\mathrm{n}$ jobs on machines $\mathrm{X}$ and $\mathrm{Y}$ correspondingly satisfying processing times structural relationship defined in equation (2) in that case for the $\mathrm{n}$ job sequence

$$
\begin{aligned}
& \varsigma: \mu_{1}, \mu_{2}, \ldots, \mu_{n} \\
& T_{\mu_{n} Y}=X^{\prime}{ }_{\mu_{1}}+Y^{\prime}{ }_{\mu_{1}}+Y^{\prime}{ }_{\mu_{2}}+\ldots+Y^{\prime} \mu_{n}
\end{aligned}
$$

Proof. Using principle of Mathematical Induction on number of jobs:

Consider $S(n): T_{\mu_{n} Y}=X_{\mu_{1}}^{\prime}+Y_{\mu_{1}}^{\prime}+Y_{\mu_{2}}^{\prime}+\ldots+Y^{\prime} \mu_{n}$

$T_{\mu_{1} X}=X^{\prime} \mu_{1}$

$T_{\mu_{1} Y}=X_{\mu_{1}}^{\prime}+Y^{\prime} \mu_{1}$

$S(n)$ is true for $n=1$.

Assume the result holds for less than $\mathrm{n}$ jobs,

$T_{\mu_{n} Y}=\operatorname{Max}\left(T_{\mu_{n} X}, T_{\mu_{n-1} Y}\right)$

As $\operatorname{Max} X^{\prime}{ }_{j} \leq \operatorname{Min} Y^{\prime}{ }_{j}$

Consequently, $T_{\mu_{n} Y}=X_{\mu_{1}}^{\prime}+Y_{\mu_{1}}^{\prime}+Y_{\mu_{2}}^{\prime}+\ldots+Y_{\mu_{n}}^{\prime}$

$S(n)$ is true for all $n \in N$

\section{Lemma}

Following the similar notations as used in B. Lemma, for $\mathrm{n}$ job sequence $\varsigma: \mu_{1}, \mu_{2}, \ldots, \mu_{n}$

$W_{\mu_{1}}=0$

$W_{\mu_{n}}=X^{\prime} \mu_{1}+\sum_{r=1}^{n-1} x_{\mu_{r}}-X^{\prime} \mu_{n}$

$x_{\mu_{r}}$ is defined as $x_{\mu_{r}}=Y^{\prime} \mu_{r}-X^{\prime} \mu_{r}, \mu_{r} \in\{1,2,3, \ldots, n\}$

Proof. $W_{\mu_{1}}=0$

$W_{\mu_{n}}=\operatorname{Max}\left(T_{\mu_{n} X}, T_{\mu_{n-1} Y}\right)-T_{\mu_{n} X}$

$W_{\mu_{n}}=X^{\prime} \mu_{1}+Y^{\prime} \mu_{1}+Y^{\prime} \mu_{2}+\ldots . .+Y^{\prime} \mu_{n-1}-X^{\prime} \mu_{1}-X^{\prime} \mu_{2}-\ldots . .-X^{\prime} \mu_{n}$

$W_{\mu_{n}}=X^{\prime} \mu_{1}+\sum_{r=1}^{n-1}\left(Y^{\prime} \mu_{r}-X^{\prime} \mu_{r}\right)-X^{\prime} \mu_{n}$

$W_{\mu_{n}}=X^{\prime} \mu_{1}+\sum_{r=1}^{n-1}\left(x_{\mu_{r}}\right)-X^{\prime} \mu_{n}$

D. Theorem

Following the similar notations as used in B. Lemma, for the $\mathrm{n}$ job sequence $\varsigma: \mu_{1}, \mu_{2}, \ldots, \mu_{n}$ the total waiting time $(W)$ is given by

$W=n X^{\prime} \mu_{1}+\sum_{r=1}^{n-1} y_{\mu_{r}}-\sum_{k=1}^{n} X^{\prime}{ }_{k}$

Where $y_{\mu_{r}}=(n-r)_{x_{\mu_{r}}} ; \mu_{r} \in\{1,2, \ldots, n\}$

Proof. Using equation (3) and equation (4) we have

$W_{\mu_{1}}=0$

For $n=2$

$W_{\mu_{2}}=X^{\prime} \mu_{1}+\sum_{r=1}^{1} x_{\mu_{r}}-X^{\prime} \mu_{2}$

For $n=3$, 
$W_{\mu_{3}}=X^{\prime} \mu_{1}+\sum_{r=1}^{2} x_{\mu_{r}}-X^{\prime} \mu_{3}$

Continuing in this way

$W_{\mu_{n}}=X^{\prime} \mu_{1}+\sum_{r=1}^{n-1} X_{\mu_{r}}-X^{\prime} \mu_{n}$

Hence total waiting time

$W=\sum_{i=1}^{n} W \mu_{i}$

$W=n X^{\prime} \mu_{1}+\sum_{r=1}^{n-1} y_{\mu_{r}}-\sum_{k=1}^{n} X^{\prime}{ }_{k}$

Where $y_{\mu_{r}}=(n-r)_{x_{r}} ; \mu_{r} \in\{1,2, \ldots, n\}$

\section{E. Equivalent Job Block Theorem}

Assuming the two machines $\mathrm{X}$ and $\mathrm{Y}$ are processing $\mathrm{n}$ jobs in the sort $\mathrm{XY} .\left\{X^{\prime}{ }_{j}\right\}_{j=1}^{n}$ and $\left\{Y^{\prime}\right\}_{j=1}^{n}$ are the processing times of job $i, 1 \leq i \leq n$ on machine $\mathrm{X}$ and $\mathrm{Y}$ respectively.(1, $\mathrm{m})$ is the group job or job block which can be made equivalent to the one job $\alpha$ (called equivalent job $\alpha$ ). Job $\alpha$ has processing times $X_{\alpha}^{\prime}$ and $Y_{\alpha}^{\prime}$ on the machines $\mathrm{X}$ and $\mathrm{Y}$ and are given by

$X_{\alpha}^{\prime}=X^{\prime}{ }_{l}+X^{\prime}{ }_{m}-\min \left(X^{\prime}{ }_{m}, Y_{l}{ }_{l}\right)$
$Y_{\alpha}{ }_{\alpha}=Y_{l}{ }_{l}+Y^{\prime}{ }_{m}-\min \left(X^{\prime}{ }_{m}, Y_{l}{ }_{l}\right)$

The theorem is proved by Maggu P.L.and et.al. [4].

\section{ALGORITHM}

Step 1: Calculate the processing times for the fictitious machines $\mathrm{X}$ and $\mathrm{Y}$ denoted by $X^{\prime}{ }_{j}$ and $Y^{\prime}{ }_{j}$ defined as in equation (1)

$$
\begin{aligned}
X^{\prime}{ }_{j} & =m_{1 j}+t_{1 \rightarrow 2, j} \\
Y^{\prime}{ }_{j} & =m_{2 j}+t_{1 \rightarrow 2, j}
\end{aligned}
$$

Step 2: Verify the processing time structural relationship $\operatorname{Max}_{X}{ }_{j} \leq \operatorname{Min}_{Y^{\prime}}{ }_{j}$ as defined in equation (2).

Step 3: Take equivalent job $\alpha=(1, \mathrm{~m})$ and calculate processing times using equations (7) and replace the pair of jobs $(1, \mathrm{~m})$ in this order by the single job $\alpha$.

Step 4: Calculate the values for $x_{j}=Y^{\prime}{ }_{j}-X^{\prime}{ }_{j}$ in the TABLE II.

Step 5: Assemble the jobs in ascending order of $x_{j}$

Assume the schedule thus found be $\left(\mu_{1}, \mu_{2}, \ldots \ldots, \mu_{n-1}\right)$.

Step 6: Find the other schedules of jobs $S_{1}, S_{2}, \ldots . ., S_{n-1}$. Where $S_{1}$ is the schedule obtained in $5^{\text {th }}$ step, schedules $\mathrm{S}_{\mathrm{i}}, 1 \leq \mathrm{i} \leq \mathrm{n}-1$ can be obtained by taking $\mathrm{i}^{\text {th }}$ job in the sequence $\mathrm{S}_{1}$ to the $1^{\text {st }}$ position and considering respite of the schedule same.

Step 7: Calculate the total waiting time $\mathrm{W}$ for all the sequences $\mathrm{S}_{1}, \mathrm{~S}_{2}, \ldots ., \mathrm{S}_{\mathrm{n}-1}$ using the equations (6)

$W=n X^{\prime} \mu_{1}+\sum_{r=1}^{n-1} y_{\mu_{r}}-\sum_{k=1}^{n} X^{\prime} k$

Where $y_{\mu_{r}}=(n-r)_{\mu_{r}} ; \mu_{r} \in\{1,2, \ldots, n\}$ 
TABLE II

\begin{tabular}{|c|c|c|c|}
\hline Job & Machine X & Machine Y & $\mathbf{x}_{\mathbf{j}}$ \\
\hline j. & $\mathbf{X}_{j}^{\prime}$ & $Y_{j}^{\prime}$ & $Y_{j}^{\prime}-X_{j}^{\prime}$ \\
\hline 1. & $\mathrm{X}_{1}^{\prime}$ & $\mathrm{Y}_{1}^{\prime}$ & $\mathrm{x}_{1}$ \\
\hline 2. & $\mathrm{X}_{2}^{\prime}$ & $\mathrm{Y}_{2}^{\prime}$ & $\mathrm{x}_{2}$ \\
\hline$\ldots$ & $\ldots$ & $\ldots$ & $\ldots$. \\
\hline$\alpha$. & $\mathrm{X}_{\alpha}^{\prime}$ & $\mathrm{Y}_{\alpha}^{\prime}$ & $\mathrm{X}_{\alpha}$ \\
\hline$\ldots$ & $\ldots$ & $\ldots$ & $\ldots$ \\
\hline n-1. & $X_{n-1}^{\prime}$ & $\mathrm{Y}_{\mathrm{n}-1}^{\prime}$ & $\mathrm{x}_{\mathrm{n}-1}$ \\
\hline
\end{tabular}

A. $C++$ program for the algorithm

\#include $<$ iostream.h $>$

\#include $<$ conio.h $>$

\#include $<$ iomanip.h $>$

\#include $<$ stdlib.h $>$

void main( )

\{

clrscr( );

float a[50], b[50], sum_p, sum_q, t[50], x_k[50], y_k[50], xk[50], tempx, tempy, tempsort,kcopy[50],temp;

int job1[50],job3[50],job4[50];

int i,j,num,job[50],jobx,minjobx;

cout $<<$ "Enter the number of jobs $\backslash n$ ";

cin $>>$ num;

cout $<<$ "Enter the processing times of Machine M1 $\backslash n "$;

for $(\mathrm{i}=0 ; \mathrm{i}<$ num $; \mathrm{i}++)$

\{

$\operatorname{cin}>>\mathrm{a}[\mathrm{i}]$

\}

cout $<<$ "Enter the processing times of Machine M2 $\backslash \mathrm{n}$ ";

for $(\mathrm{i}=0 ; \mathrm{i}<$ num $; \mathrm{i}++)$

\{

$\operatorname{cin}>>b[\mathrm{i}]$

\}

cout $<<" \backslash$ nEnter the transportation times $\backslash n "$;

for $(\mathrm{i}=0 ; \mathrm{i}<$ num; $\mathrm{i}++)$

\{

$\operatorname{cin}>>\mathrm{t}[\mathrm{i}]$;

\}

cout $<<$ "Fictitious Machine $X \backslash n "$;

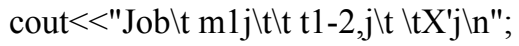

float sumx_k $=0.0$;

for $(\mathrm{i}=0 ; \mathrm{i}<$ num; $;++)$

\{

jobx $=\mathrm{i}+1$;

$\mathrm{x}_{-} \mathrm{k}[\mathrm{i}]=\mathrm{a}[\mathrm{i}]+\mathrm{t}[\mathrm{i}]$;

sumx_k=sumx_k+x_k[i];

cout $<<$ jobx $<<"|\mathrm{t} "<<\mathrm{a}[\mathrm{i}]<<"| \mathrm{t}+|\mathrm{t} "<<\mathrm{t}[\mathrm{i}]<<" \backslash \mathrm{t}=| \mathrm{t}$ " $<<\mathrm{x} \_\mathrm{k}[\mathrm{i}]<<" \mid \mathrm{n}$ ";

$$
\text { \} }
$$




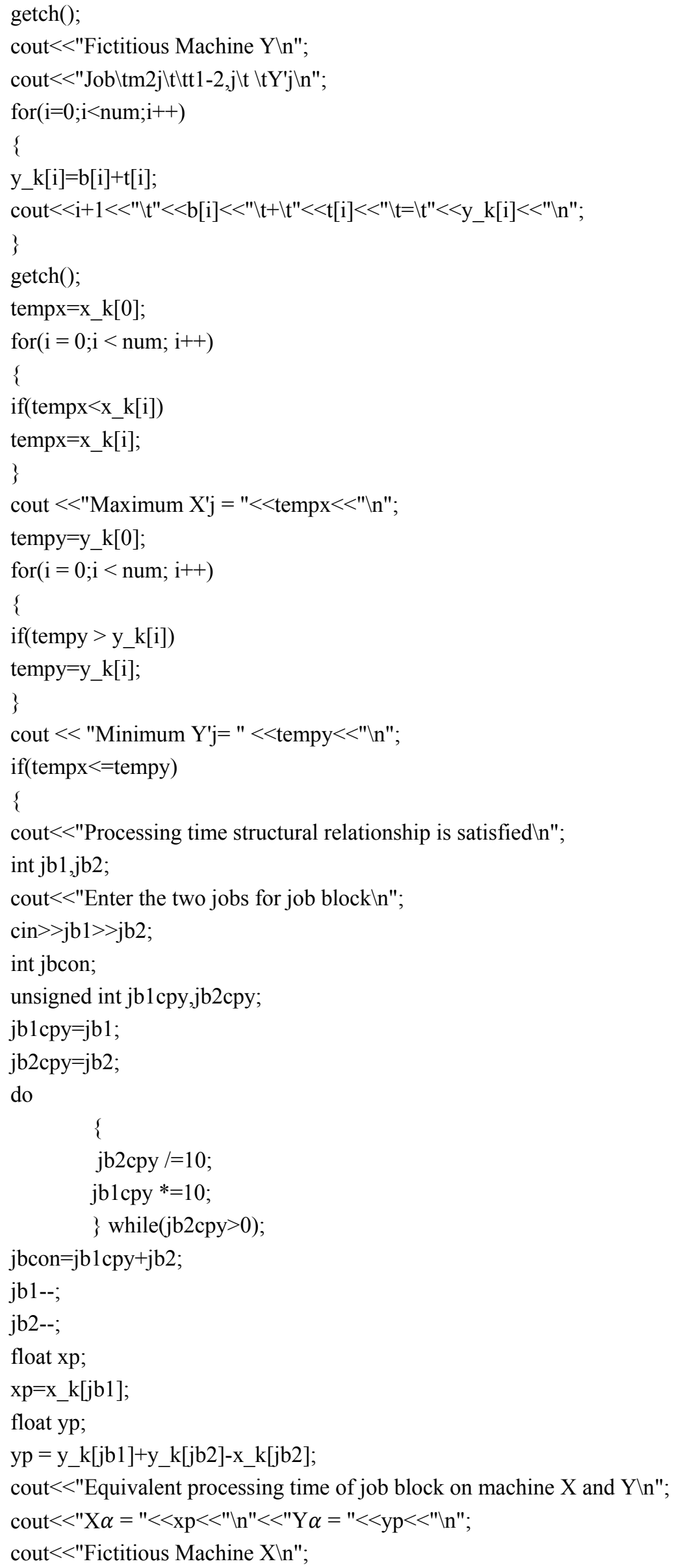




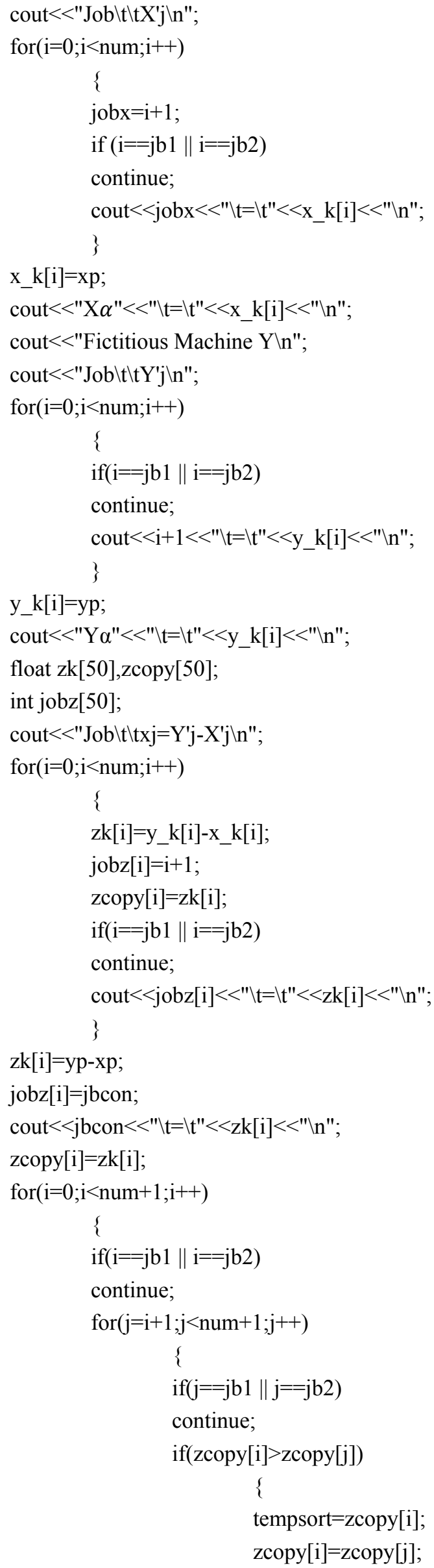




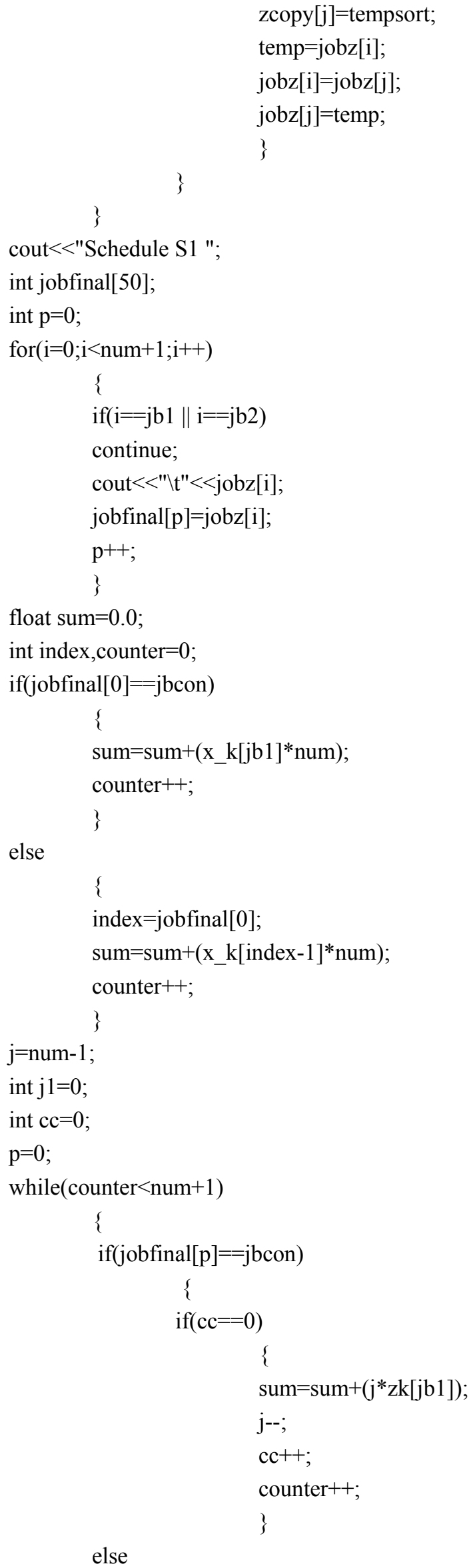




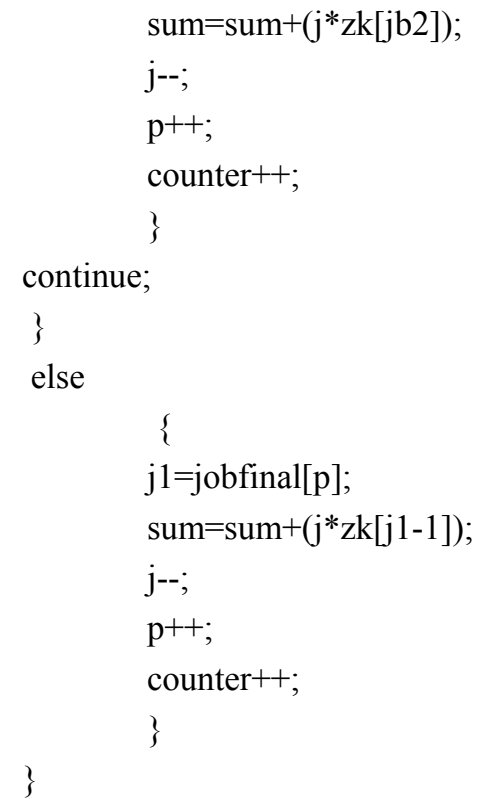

float sumfinal[50];

sumfinal[0]=sum-sumx_k;

cout $<<"$ "nWaiting Time $\mathrm{W}="<<$ sumfinal[0];

getch () ;

cout $<<" \backslash$ nOther Possible schedules are: $\backslash n "$;

int $\mathrm{pp}=1, \mathrm{~m}=0$;

while $(\mathrm{pp}<$ num-1)

\{

int templl=jobfinal[0];

jobfinal $[0]=$ jobfinal $[\mathrm{pp}]$;

jobfinal $[\mathrm{pp}]=$ templl;

cout $<<" \backslash$ nSchedule $\mathrm{S} "<<++$ pp;

for $(\mathrm{i}=0 ; \mathrm{i}<$ num $-1 ; \mathrm{i}++)$

\{

cout $<<" \mid \mathrm{t} "<<$ jobfinal $[\mathrm{i}]$;

\}

getch();

sum $=0.0$;

index, counter $=0$;

if (jobfinal $[0]==$ jbcon $)$

\{

$\operatorname{sum}=\operatorname{sum}+\left(x \_k[j b 1]^{*}\right.$ num $)$;

counter++;

\}

else

\{

index $=$ jobfinal $[0]$;

sum $=$ sum $+\left(x \_k[\text { index-1 }]^{*}\right.$ num $)$;

counter++;

\}

$\mathrm{j}=$ num -1 ;

int $\mathrm{j} 1=0$; 


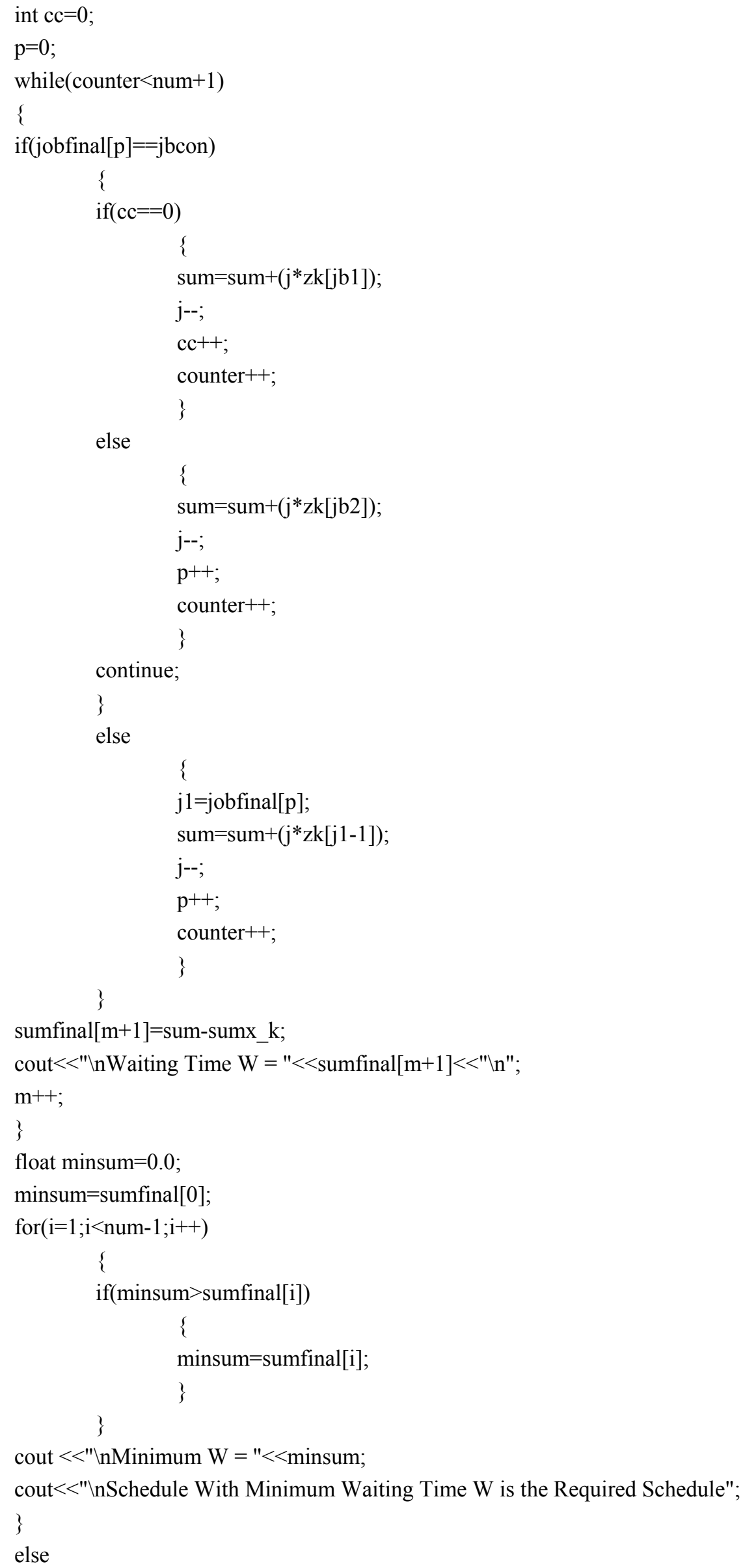




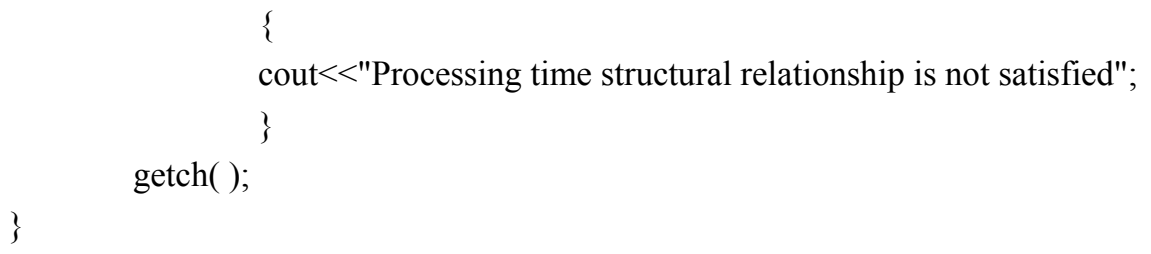

\section{B. Numerical Illustration}

Assuming 5 jobs are to be processed in Flow Shop on two machines $M_{1}$ and $M_{2}$. Assuming the entries for TABLE I with $n=5$ can be seen in TABLE III.

Our intention is to attain most favorable schedule of jobs lessening the total of the waiting time for all the jobs by considering 3,5 in a block $(3,5)$.

\section{Solution}

As per step 1- Calculate the processing time for the fictitious machines $\mathrm{X}$ and $\mathrm{Y}$ in TABLE IV as defined in [6], [16], [18] given by equations(1).

As per step 2: $\operatorname{Max} X^{\prime}{ }_{j}=\operatorname{Min}_{Y^{\prime}}{ }_{j}=8$, hence the processing time structural relationship defined in equation (2) is satisfied.

As per step 3- Taking $(3,5)$ as a job block denoting this job block by $\alpha$. The processing times on both of the machines $\mathrm{X}$ and $\mathrm{Y}$ for single job $\alpha$ are calculated using equations (7):

$$
\begin{aligned}
& X^{\prime}{ }_{\alpha}=X_{{ }_{3}}+X_{{ }_{5}}-\min \left(X_{{ }_{5},}, Y_{3}{ }_{3}\right)=8 \\
& Y^{\prime}{ }_{\alpha}=Y^{\prime}{ }_{3}+Y_{{ }_{5}}-\min \left(X_{5}{ }_{5}, Y_{3}{ }_{3}\right)=19
\end{aligned}
$$

As per step 4: Finding the values for $x_{j}=Y^{\prime}{ }_{j}-X^{\prime}{ }_{j}$ for the given problem in TABLE V.

As per step 5- Assemble the jobs in ascending order of $x_{j}$. The schedule $S_{1}$ thus found be 1, 2, 4, $\alpha$.

As per step 6- Consider the other possible schedules

$\mathrm{S}_{1}: 1,2,4, \alpha ; \mathrm{S}_{2}: 2,1,4, \alpha ; \mathrm{S}_{3}: 4,1,2, \alpha ; \mathrm{S}_{4}: \alpha, 1,2,4$

As per step 7- Calculate the total of the waiting time (W) of all the jobs for the sequences $S_{1}, S_{2}, S_{3}, S_{4}$ using equations (6)

For this problem $\sum_{j=1}^{5} X^{\prime}{ }_{j}=24$

For the sequence $\mathrm{S}_{1}: 1,2,4, \alpha$ or $\mathrm{S}_{1}: 1,2,4,3,5$

$\mathrm{W}=53$

For the sequence $S_{2}: 2,1,4, \alpha$ or $S_{2}: 2,1,4,3,5$

$\mathrm{W}=52$

For the sequence $S_{3}: 4,1,2, \alpha$ or $S_{3}: 4,1,2,3,5$

$\mathrm{W}=51$

For the sequence $S_{4}: \alpha, 1,2,4$ or $S_{4}: 3,5,1,2,4$

$\mathrm{W}=63$

Hence schedule $S_{3}: 4,1,2,3,5$ is the requisite schedule with waiting time 51 with consideration of $(3,5)$ as a group job.

\section{CONCLUSION}

The idea of lessening the total of the waiting time for all the jobs in the flow shop scheduling is very significant in the case when the manufacturer or producer has a bond with the customers to made their work without waiting for too much time. Though it may raise the other costs such as penalty cost of the jobs or the total elapsed time etc. By taking into account the various parameters like time to set up the machines, time consumed in breakdown of machines etc. the study can be further generalized. 
TABLE III

\begin{tabular}{|c|c|c|c|}
\hline Job & Machine $\mathbf{M}_{\mathbf{1}}$ & Transportation time & Machine $\mathbf{M}_{\mathbf{1}}$ \\
\hline $\mathbf{j .}$ & $\mathbf{m}_{\mathbf{1} \mathbf{j}}$ & $\mathbf{t}_{\mathbf{1} \rightarrow \mathbf{2} \mathbf{j}}$ & $\mathbf{m}_{\mathbf{2} \mathbf{j}}$ \\
\hline 1. & 3 & 2 & 6 \\
\hline 2. & 1 & 3 & 8 \\
\hline 3. & 6 & 2 & 7 \\
\hline 4. & 2 & 1 & 11 \\
\hline 5. & 2 & 2 & 12 \\
\hline
\end{tabular}

TABLE IV

\begin{tabular}{|c|c|c|}
\hline Job & Machine $\mathbf{X}$ & Machine $\mathbf{~}$ \\
\hline $\mathbf{j .}$ & $\mathbf{X}_{\mathbf{j}}$ & $\mathbf{Y}_{\mathbf{j}}{ }_{\mathbf{j}}$ \\
\hline 1. & 5 & 8 \\
\hline 2. & 4 & 11 \\
\hline 3. & 8 & 9 \\
\hline 4. & 3 & 12 \\
\hline 5. & 4 & 14 \\
\hline
\end{tabular}

TABLE V

\begin{tabular}{|c|c|c|c|}
\hline Job & Machine $\mathbf{X}$ & Machine $\mathbf{Y}$ & $\mathbf{x}_{\mathbf{j}}$ \\
\hline $\mathbf{j .}$ & $\mathbf{X}_{\mathbf{j}}$ & $\mathbf{Y}_{\mathbf{j}}$ & $\mathbf{Y}_{\mathbf{j}}-\mathbf{X}_{\mathbf{j}}$ \\
\hline 1. & 5 & 8 & 3 \\
\hline 2. & 4 & 11 & 7 \\
\hline$\alpha$. & 8 & 19 & 11 \\
\hline 4. & 3 & 12 & 9 \\
\hline
\end{tabular}

\section{REFERENCES}

[1] Johnson, Optimal two and three stage production schedule with set up times included ,Naval Res Log Quart, 1954, Vol. 1.

[2] Ignall E. and Schrage L.E., Application of branch and bound techniques to some flow shop problems, Operation Research, 1965, Vol.13.

[3] Lockett, A.G. and Muhlemann, A.P., Technical notes: a scheduling Problem involving sequence dependent changeover times, Operation Research, 1972, Vol.20.

[4] Maggu P.L. and Dass G., Equivalent jobs for job block in job sequencing, Operations Research, 1977, Vol.14, No. 4.

[5] Bhatnagar V., Das G., and Mehta O.P., n-job two machine flow-job shop scheduling problem having minimum total waiting time for all jobs, PAMS, 1979, Vol.X, No.1-2

[6] Singh T.P., On $\mathrm{n} \times 2$ shop problem involving job block, transportation times and Break-down Machine times, PAMS, 1985, Vol.XXI, No.1-2.

[7] Gupta, J.N.D.,Flow shop schedules with sequence dependent setup times,Journal of the Operations Research Society of Japan, 1986, Vol.29.

[8] Rajendran, C. and Chaudhuri, D.,An efficient heuristic approach to the scheduling of jobs in a flow-shop, European Journal of Operational Research, 1992, Vol.61.

[9] Singh T.P., Gupta D. and Kumar R., Optimal two stage production schedule with Group job-restrictions having set up times separated from processing time associated with probabilities, Reflections des ERA, (JMS), 2006, Vol.I.

[10] Singh T.P., Gupta D. \& Kumar R., Bi-criteria in scheduling under specified rental policy, processing time associated with probabilities including job block concept, Presented at National Conference on information technology at NCCEI, March 18-20, 2006.

[11] Narrain L., Gupta D. \& Kumar R., Minimization rental cost under specified rental policy in two stage flow shop the processing times associated with probabilities including job block criteria, Reflections des ERA, (JMS), 2006, Vol. 2.

[12] Singh V., Three machines flow shop scheduling problems with total rental cost, International referred journal, Jan 2011,Vol.-II.

[13] Gupta D., Minimizing rental cost under specified rental policy in two stage flow shop, the processing time associated with probabilities including break down interval and job block criteria, European Journal of Business and Management (USA, 2011), Vol.3, No.2.

[14] Gupta D. and Goyal B., Optimal scheduling for total waiting time of jobs in specially structured two stage Flow Shop Scheduling with processing times associated with probabilities, Aryabhatta Journal of Mathematics \& Informatics, Jan- June 2016, Vol.8, No. 1.

[15] Gupta D. et. al a. Specially Structured Two Stage Flow Shop Scheduling To Minimize The Rental Cost, Processing Time Each Associated With Probabilities Including Weightage of Jobs, International Journal of Research in Management, 2012, Vol.2, No.2.

[16] Gupta D. et. al b. $\mathrm{n} \times 2$ Specially Structured Flow Shop Scheduling with Transportation Time to Minimize the Rental Cost of Machines, International Journal of Mathematical Archive, 2012, Vol.3 No.2.

[17] Gupta D. and Goyal B. Job block concept in two stage specially structured Flow shop scheduling to minimize the total waiting time of jobs, International Journal of Latest Trends in Engineering and Technology, 2016, Vol.7, No.3.

[18] Gupta D. and Goyal B. Optimization of Total Waiting Time of Jobs in Two Stage Specially Structured Flow Shop Scheduling Model with Transportation Time of Jobs, International Journal on Future Revolution in Computer Science \& Communication Engineering, 2018, Vol.4, No.3. 